\title{
PEMANFAATAN LAMPU LED UNTUK PENINGKATAN HASIL TANGKAPAN PADA KAPAL HAND LINE DI KENDARI
}

\author{
AGUS WAHYU SANTOSO, MULYONO S. BASKORO, \\ BUDHI H. ISKANDAR, \& YOPI NOVITA \\ Departemen Pemanfaatan Sumberdaya Perikanan, \\ Fakultas Perikanan dan Ilmu Kelautan, \\ Institut Pertanian Bogor, Bogor 16680, Indonesia \\ Email:agusws@yahoo.com
}

\begin{abstract}
ABSTRAK
Kapal penangkap ikan hand line di Kendari Indonesia sebagian besar dioperasikan tanpa dilengkapi alat bantu penangkapan ikan. Oleh karena itu untuk meningkatkan produktifitasnya maka diperlukan alat bantu penangkapan ikan seperti lampu LED. Tujuan penelitian ini adalah membandingkan efektifitas hasil tangkapan kapal ikan (hand line) yang dilengkapi dengan lampu LED dengan hasil tangkapan tanpa menggunakan lampu LED. Lokasi penelitian dilakukan sekitar perairan bagian timur Kota Kendari, Indonesia. Metode penelitian yang dilakukan adalah dengan metode experimental fishing, dimana peneliti langsung melakukan eksperimen penangkapan ikan di lapangan untuk mengambil data. Hasil penelitian menunjukkan bahwa Lampu LED pada kapal penangkap ikan memberikan hasil tangkapan yang lebih banyak sekitar $22.30 \%$ dibandingkan dengan kapal penangkap ikan yang tanpa menggunakan lampu LED. Jenis jenis ikan yang ditangkap adalah: Decapterus sp, Rastrelliger sp, Sardinella sp, Selaroides sp, Coryphaenidae sp, Euthynnus Affinis, Lutjanus Sp, dan Epinephelus Sp. Dengan demikian kapal ikan (hand line) yang diberikan kepada nelayan sebagai kapal bantuan dapat bermanfaat secara maksimal.
\end{abstract}

Kata Kunci: Penangkapan Ikan, Lampu LED, Produktifitas, Jenis Ikan.

\section{PENDAHULUAN}

Penggunaan lampu listrik untuk menarik perhatian ikan pelagis kecil untuk tujuan penangkapan ikan di Indonesia, telah berkembang dengan baik. Akan tetapi penelitian dengan kapal penangkap ikan masih sangat sedikit, karena penelitian lampu sebagai alat bantu banyak dilakukan di bagan tancap atau perahu bagan. Tetapi pemanfaatan teknologi cahaya pada bagan tancap masih bersifat sederhana. Untuk meningkatkan kemampuan teknologi dari alat tangkap bagan tancap maka beberapa penelitian telah dilakukan oleh para ahli. Diantaranya adalah dalam hubungannya dengan penggunaan penerangan cahaya dengan lampu petromaks, penggunaan 4, 6 dan 8 unit lampu tidak menunjukkan perbedaan yang nyata (Herutomo, 1995). Dialain pihak Efendy (1998) melaporkan bahwa berat hasil tangkapan total yang diperoleh pada bagan tancap di perairan Teluk Awur Jepara Jawa Tengah dipengaruhi oleh jumlah lampu, dimana setiap penambahan jumlah lampu terjadi peningkatan hasil tangkapan, namun tidak ada perbedaan yang nyata antara 4 dan 5 unit lampu. Selanjutnya telah dilaporkan bahwa berdasarkan analisis deskriptif terhadap hasil tangkapan menunjukkan bahwa komposisi hasil tangkapan dominan untuk setiap jumlah lampu tidak sama. Penggunaan 2 unit lampu menghasilkan tangkapan dominan yaitu udang rebon, 3 unit lampu menghasilkan tangkapan dominan teri, 4 unit lampu menghasilkan tangkapan dominan ikan tembang dan 5 unit lampu menghasilkan tangkapan dominan ikan layur.

Penelitian penggunaan lampu untuk penangkapan ikan di Indonesia selanjutnya lebih berkembang lagi, tidak hanya terbatas pada alat dan hasil tangkapannya tetapi juga mekanisme tertariknya ikan oleh cahaya atau hal 
yang berhubungan dengan tingkah laku ikan terhadap cahaya. Sampai berapa lama waktu pencahayaan baru dilakukan penarikan jaring. Hasil penelitian menunjukkan bahwa setiap jenis ikan berbeda responnya terhadap cahaya. Ikan teri merespon cahaya secara cepat, sehingga pengangkatan jaring 4-5 kali dalam semalam dapat dilakukan. Selanjutnya ikan teri lebih cenderung pada iluminasi cahaya yang tinggi (Sudirman et al, 2004a; 2004b). Seiring dengan perkembangan teknologi, khususnya pemanfaatan cahaya dalam aktivitas penangkapan ikan, maka teknologi tersebut dapat pula diterapkan pada alat penangkapan ikan pada bagan tancap. Serangkaian uji coba telah dilakukan untuk mengamati penggunaan berbagai jenis lampu (neon, pijar dan merkuri) pada bagan tancap di Selat Makassar. Hal ini disebabkan karena jenis lampu akan mempengaruhi ketertarikan ikan disekitar alat penangkapan. Maka penelitian ini difokuskan pada kapal penangkap ikan yang dilengkapi dengan bantuan lampu LED sebagai alat bantu untuk menarik ikan untuk mendekat kemudian akan dipancing dengan menggunakan alat tangkap Hand Line.

\section{METODE PENELITIAN}

\section{Lokasi Penelitian:}

Penelitian dilakukan pada bulan Juli 2017 sampai November 2018 di perairan bagian Timur Kota Kendari, Provinsi Sulawesi Tenggara, Indonesia. Lokasi tersebut merupakan salah satu daerah pesisir di Provinsi Sulawesi Tenggara, dan merupakan daerah penangkapan ikan yang memiliki potensi perikanan cukup besar di Indonesia. Berada di antara 3'54'30" - 4'3'11" Lintang Selatan dan $122^{\circ} 23^{\prime}-122^{\circ} 39^{\prime}$ Bujur Timur.

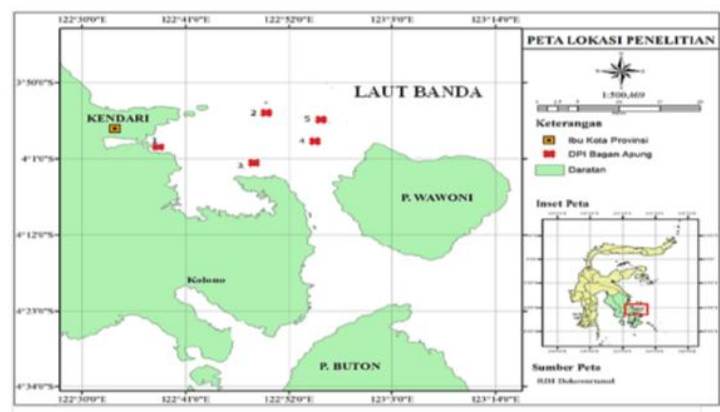

Gambar 1. Lokasi Penelitian

\section{Metode Pengumpulan Data}

Metode penelitian yang dilakukan adalah dengan metode experimental fishing, dimana peneliti langsung melakukan eksperimen penangkapan ikan di lapangan untuk mengambil data. Obyek penelitian yaitu ikan hasil tangkapan pada kapal penangkapan ikan hand line yang menggunakan alat bantu cahaya (light fishing) dan yang tidak menggunakan cahaya. Lampu yang digunakan berjumlah 6 buah 3 disamping kanan kapal dan 3 disamping kiri kapal, dipasang dengan meng-gantungkannya di tiang, kira-kira 1 meter di atas permukaan air, sedangkan lampu LED yang digunakan adalah lampu neon bulat LED berkekuatan 16 watt. Uji coba penangkapan ikan dilakukan mulai jam 18.00 (sore) sampai jam 06.00 (pagi hari) atau selama 12 jam. Setiap operasi penangkapan ikan rata-rata 2 jam, dan dalam satu malam ada 6 kali operasi penangkapan ikan. Selama 5 malam, masing-masing ada 15 kali operasi penangkapan secara bergantian.

\section{Distribusi Iluminasi Cahaya Dalam Air}

Berikut ini disampaikan pola sebaran iluminasi cahaya dalam air dengan menggunakan lampu normal yang di ukur secara horizontal dan vertikal.
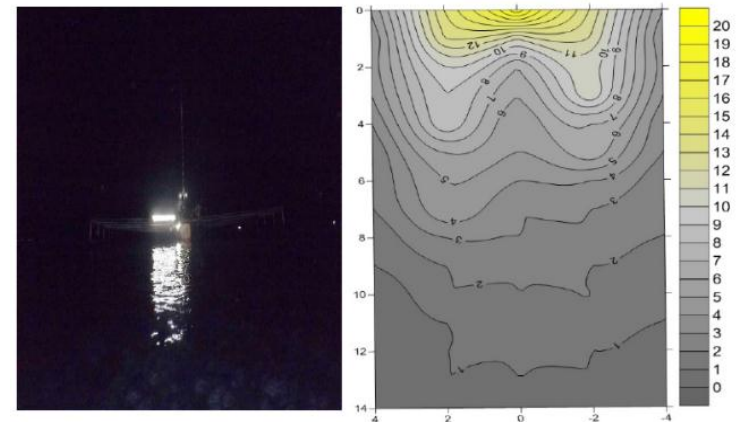

Gambar 2. Pola sebaran iluminasi cahaya lampu.

Nilai iluminasi cahaya pada sisi sebelah kanan perahu cahaya yang terbaca berada pada jarak $4 \mathrm{~m}$, dan sisi sebelah kiri perahu cahaya yang terbaca juga berada pada jarak $4 \mathrm{~m}$. Nilai pengukuran secara horizontal intensitas cahaya sangat rendah karena lampu yang digunakan di atas perahu ditempatkan hanya di sisi sebelah kanan dan di samping kiri perahu. Pengukuran secara vertikal dengan tiap-tiap jarak pengukuran $1 \mathrm{~m}$ sampai pada kedalaman yang tidak terbaca oleh underwater lux meter. Cahaya underwater lux meter nilai yang paling tertinggi yaitu 20 lux dengan kedalaman $(0 \mathrm{~m})$ atau di permukaan perahu, sedangkan yang paling terendah cahaya yang masuk secara vertikal pada kedalam $14 \mathrm{~m}$. 
Pengambilan data primer dilakukan dengan mengidentifikasi komposisi jenis ikan dan jumlah ikan yang tertangkap pada kapal Hand Line. Pengambilan data komposisi jenis ikan yang tertangkap dilakukan dengan mengidentifikasi jenis dan jumlah ikan hasil tangkapan. Data sekunder dikumpulkan melalui studi literatur. Data sekunder terdiri dari informasi mengenai jenis ikan dan plankton. Data terkait konsentrasi klorofil di lokasi penelitian diperoleh dari informasi data citra satelit aqua modis level 3 dari NASA: http://oceancolor.gsfc.nasa.gov/. Citra satelit aqua modis merupakan satelit ilmu pengetahuan tetang bumi yang dimiliki NASA (National Aeronautics and Space Administration). Simbolon et al. (2009), menjelaskan tujuan utama citra satelit aqua modis yaitu memahami proses yang saling berhubungan antara atmosfer, laut dan daratan dengan perubahan sistem cuaca dan pola iklim di bumi.

\section{Analisis Data}

Dalam penelitian ini digunakan analisis deskriptif kuantitatif untuk menggambarkan atau mengilustrasikan obyek penelitian melalui sampel data yang telah ditentukan. Menurut Sugiono (2013) metode ini juga dapat digunakan untuk memformulasikan komposisi jenis dan ukuran ikan di daerah penangkapan ikan.

\section{HASIL DAN PEMBAHASAN}

Hasil uji coba yang telah dilakukan pada penggunaan lampu LED (light fishing) sebagai alat bantu penangkapan ikan di kapal hand line, menunjukkan bahwa cahaya lampu LED mampu menarik ikan agar datang mendekati kapal hand line tersebut. Kondisi ini memudahkan nelayan melakukan penangkapan ikanikan tersebut. Kami menemukan bahwa penggunaan lampu LED pada kapal hand line telah meningkatkan hasil tangkapan ikan.

\section{Komposisi Jumlah Tangkapan}

Hasil tangkapan spesies ikan pada lima lokasi daerah penangkapan ikan menggunakan Hand line terdiri dari 8 spesies. Jenis ikan yang paling banyak tertangkap adalah Euthynnus affinis. Hasil tangkapan ikan Euthynnus affinis terbanyak pada DPI 2 dan 6 yaitu perairan Pulau Wawoni dan Saponda Utara. Hasil tangkapan ikan Euthynnus affinis lebih tinggi dari pada spesies lainnya disebabkan kondisi daerah penangkapan ikan sesuai dengan habitatnya. Kedalaman perairan di daerah penangkapan ikan mencapai $50-150 \mathrm{~m}$, suhu permukaan laut $26^{\circ} \mathrm{C}-29^{\circ} \mathrm{C}$, salinitas $32 \%$ $34 \%$ dan konsentrasi klorofil-a $0,1 \mathrm{mg} / \mathrm{m} 3-0,4$ $\mathrm{mg} / \mathrm{m} 3$.

Tabel 1. Hasil tangkapan ikan dari kapal hand line yang menggunakan lampu LED

\begin{tabular}{|c|c|c|c|c|c|c|c|c|c|}
\hline \multirow{2}{*}{ No } & \multirow{2}{*}{ Type of Fish } & \multicolumn{8}{|c|}{ Fishing Grounds ( $\mathrm{Kg}$ ) } \\
\hline & & 1 & 2 & 3 & 4 & 5 & Total & $\%$ & Average \\
\hline 1 & Decapterus sp & 21 & 24 & 0 & 20 & 29 & 94 & 25.20 & 18.80 \\
\hline 2 & Rastrelliger sp & 0 & 22 & 8 & 10 & 8 & 48 & 12.87 & 9.60 \\
\hline 3 & Caranx Bartholo sp & 0 & 10 & 0 & 6 & 0 & 16 & 4.29 & 3.20 \\
\hline 4 & Selaroides sp & 12 & 0 & 18 & 0 & 16 & 46 & 12.33 & 9.20 \\
\hline 5 & Coryphaenidae sp & 0 & 8 & 0 & 14 & 0 & 22 & 5.90 & 4.40 \\
\hline 6 & Euthynnus affinis & 20 & 35 & 22 & 0 & 22 & 99 & 26.54 & 19.80 \\
\hline 7 & Lutjanus Sp & 5 & 0 & 4 & 0 & 15 & 24 & 6.43 & 4.80 \\
\hline 8 & Epinephelus Sp & 4 & 0 & 2 & 11 & 7 & 24 & 6.43 & 4.80 \\
\hline & Total & 62 & 99 & 54 & 61 & 97 & 373 & 100.00 & 9.33 \\
\hline
\end{tabular}

Pada Tabel 1 menunjukkan bahwa kapal hand line yang menggunakan lampu LED yang beroperasi di lima daerah penangkapan ikan, telah menangkap jenis ikan pelagis kecil seperti jenis ikan Decapterus sp dengan berat total sebanyak $94 \mathrm{~kg}$ (25.20\%), Rastrelliger sp sebanyak $48 \mathrm{~kg}$ (12.87), Caranx Bartholomaei sp sebanyak $16 \mathrm{~kg}$ (4.29\%), Selaroides sp sebanyak $46 \mathrm{~kg}$ (12.33\%), Coryphaenidae sp sebanyak $22 \mathrm{~kg}(5.90 \%)$. Sedangkan jenis ikan pelagis besar yang tertangkap adalah Euthynnus affinis sebanyak $99 \mathrm{~kg}(26.54 \%)$, Lutjanus Sp $24 \mathrm{~kg}$ (6.43\%), dan Epinephelus Sp sebanyak $24 \mathrm{~kg}$ (6.43\%). Jenis ikan pelagis kecil yang paling banyak tertangkap adalah Decapterus sp sedangkan jenis ikan pelagis besar yang paling banyak tertangkap adalah Euthynnus affinis. Total hasil tangkapan ikan pelagis kecil sebesar $60.59 \%$ (226 kg) lebih besar dari hasil tangkapan ikan pelagis besar yang hanya $39.41 \%(147 \mathrm{~kg})$. Sementara itu total semua hasil tangkapan hand line yang menggunakan alat bantu lampu LED dari lima daerah penangkapan ikan adalah sebesar 373 $\mathrm{kg}$.

Tabel 2. Hasil tangkapan ikan dari kapal hand line tanpa menggunakan lampu LED

\begin{tabular}{llrrrrrrrr}
\hline \multirow{2}{*}{ No } & \multirow{2}{*}{ Type of Fish } & \multicolumn{8}{c}{ Fishing Gromds (Kg) } \\
\cline { 2 - 10 } & \multicolumn{1}{c}{$\mathbf{1}$} & $\mathbf{2}$ & $\mathbf{3}$ & $\mathbf{4}$ & 5 & Total & \multicolumn{1}{c}{$\%$} & Average \\
\hline 1 & Decapterus sp & 14 & 10 & 0 & 10 & 19 & 53 & 22.36 & 10.60 \\
2 & Rastrelliger sp & 0 & 10 & 6 & 7 & 6 & 29 & 12.24 & 5.80 \\
3 & Caranx Bartholo sp & 0 & 8 & 0 & 4 & 0 & 12 & 5.06 & 2.40 \\
4 & Selaroides sp & 8 & 0 & 12 & 0 & 10 & 30 & 12.66 & 6.00 \\
5 & Coryphaenidae sp & 0 & 4 & 0 & 10 & 0 & 14 & 5.91 & 2.80 \\
6 & Euthymnus affinis & 12 & 20 & 14 & 0 & 18 & 64 & 27.00 & 12.80 \\
7 & Lutjanus Sp & 3 & 0 & 1 & 0 & 15 & 19 & 8.02 & 3.80 \\
8 & Epinephelus Sp & 3 & 0 & 1 & 7 & 5 & 16 & 6.75 & 3.20 \\
& Total & 40 & 52 & 34 & 38 & 73 & 237 & 100.00 & 5.93 \\
\hline
\end{tabular}


Pada Tabel 2 menunjukkan bahwa kapal hand line tanpa menggunakan lampu LED yang beroperasi di lima daerah penangkapan ikan, telah menangkap jenis ikan pelagis kecil seperti Decapterus sp dengan berat total sebanyak $53 \mathrm{~kg}$ (22.36\%), Rastrelliger sp sebanyak $29 \mathrm{~kg}$ (12.24), Caranx Bartholomaei sp sebanyak $12 \mathrm{~kg}(5.06 \%)$, Selaroides $\mathrm{sp}$ sebanyak $30 \mathrm{~kg}$ (12.66\%), Coryphaenidae sp sebanyak $14 \mathrm{~kg}(5.91 \%)$. Sedangkan jenis ikan pelagis besar yang tertangkap adalah Euthynnus affinis sebanyak $64 \mathrm{~kg}(27.00 \%)$, Lutjanus Sp $19 \mathrm{~kg}(8.02 \%)$, dan Epinephelus Sp sebanyak $6.75 \mathrm{~kg}(3.20 \%)$. Sama seperti hasil tangkapan dengan kapal hand line yang menggunakan lampu LED, dimana jenis ikan pelagis kecil yang paling banyak tertangkap adalah Decapterus sp sedangkan jenis ikan pelagis besar yang paling banyak tertangkap adalah Euthynnus affinis. Total hasil tangkapan ikan pelagis kecil sebesar 58.24\% (138 $\mathrm{kg}$ ) lebih besar dari hasil tangkapan ikan pelagis besar yang hanya $41.77 \%(99 \mathrm{~kg})$. Sementara itu total semua hasil tangkapan hand line yang menggunakan alat bantu lampu LED dari lima daerah penangkapan ikan adalah sebesar $273 \mathrm{~kg}$.

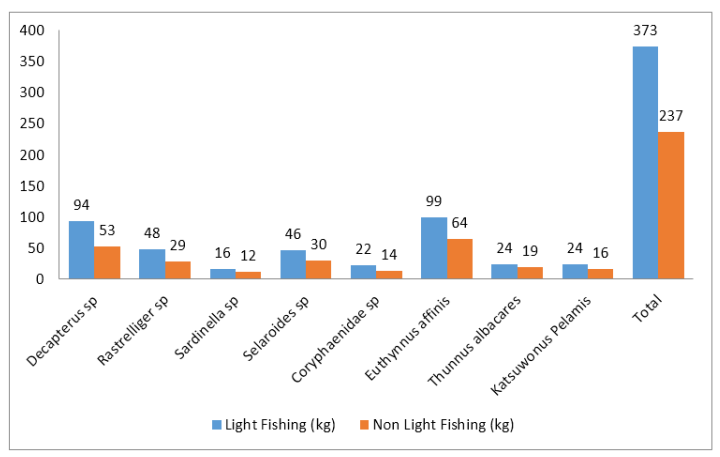

Gambar 3. Perbandingan hasil tangkapan antara kapal hand line dengan lampu LED dengan kapal hand line tanpa lampu LED.

Jika dilihat pada gambar 3. Jumlah hasil tangkapan dari semua jenis ikan di dominasi oleh hasil tangkapan dari kapal dengan menggunakan lampu LED. Dari hasil penelitian yang telah dilakukan menunjukan bahwa total hasil tangkapan dari kapal hand line yang menggunakan alat bantu lampu LED lebih banyak $22.30 \%$ dari pada total hasil tangkapan dari kapal hand line yang tanpa menggunakan lampu LED.

\section{Komposisi Jenis Ikan}

Ikan hasil tangkapan yang diperoleh dari kapal hand line sebaiknya di identifikasi sesuai jenisnya agar dapat metode penangkapan ikan dapat terus dikembangkan sesuai dengan dominasi jenis ikan yang ditangkap (Allen, et. al. 2000). Dari hasil identifikasi yang telah dilakukan terdapat delapan jenis ikan yang tertangkap, yaitu lima jenis ikan dari kelompok pelagis kecil Decapterus sp, Rastrelliger sp, Caranx Bartholomaei sp, Selaroides sp, dan Coryphaenidae) dan tiga jenis ikan dari kelompok pelagis besar (Euthynnus affinis, Lutjanus Sp, dan Epinephelus Sp). Komposisi spesies yang tertangkap pada Hand Line relatif sedikit, hal ini dipengaruhi oleh kondisi daerah penangkapan ikan umumnya terletak pada kedalaman 50 m. Sudirman dan Nesa (2011) menjelaskan kemampuan cahaya merkuri secara vertikal dapat mencapai kedalaman 27 $\mathrm{m}$ dan secara horizontal pada jarak $50 \mathrm{~m}$. Jenis ikan pelagis pada malam hari umumnya berada pada kedalaman 20-30 m. Hal ini menyebabkan spesies yang berada pada kedalaman lebih dari $27 \mathrm{~m}$ tidak dapat menangkap cahaya yang berasal dari Hand Line, sehingga jumlah spesies yang berada di catchable area relatif sedikit.

Spesies yang paling dominan secara kumulatif di daerah penangkapan hand line yaitu Euthynnus affinis. Spesies ini menyebar merata di seluruh daerah penangkapan ikan. Hasil tangkapan ikan tongkol terbanyak pada DPI 2 dan 5 yaitu perairan Pulau Wawoni dan Saponda Utara. Hasil tangkapan ikan tongkol lebih tinggi daripada spesies lainnya disebabkan kondisi daerah penangkapan ikan sesuai dengan habitatnya. Simbolon (2011) menjelaskan bahwa Euthynnus affinis pada usia belum dewasa mampu beradaptasi dengan kisaran suhu perairan $27^{\circ} \mathrm{C}-29^{\circ} \mathrm{C}$. Suhu permukaan laut pada DPI 2 dan 5 berkisar $26{ }^{\circ} \mathrm{C}-27{ }^{\circ} \mathrm{C}$. Syahdan et al. (2007) menjelaskan bahwa suhu permukaan laut perairan bagian timur Sulawesi Tenggara pada musim peralihan barat lebih hangat berkisar $25{ }^{\circ} \mathrm{C}-26{ }^{\circ} \mathrm{C}$. Peristiwa ketertarikan ikan secara langsung oleh cahaya menyebabkan ikan berkumpul di catcable area. Berkumpulnya ikan di catchable area secara tidak langsung membentuk daerah penangkapan ikan dan terbentuk pola struktur dalam rantai makanan yang disebut tropik level (Baskoro dan Effendi 2005, Simbolon et 
al. 2009).

\section{Trofik Level}

Keanekaragaman spesies yang relatif tinggi pada perikanan light fishing menyebabkan ada interaksi antara satu spesies dengan biota lainnya dalam daerah penangkapan ikan umumnya disebabkan adanya proses pemangsaan. Proses pemangsaan yang terjadi menggambarkan perpindahan energi secara berurutan. Odum (1998) menjelaskan bahwa jenjang tropik menggambarkan tahapan transfer material atau energi dari setiap jenjang atau kelompok ke jenjang berikutnya, yang dimulai dengan produser primer, konsumer primer (herbivora), skunder, tersier, dan seterusnya dan diakhiri dengan predator di puncak jaring. Tropik level yang terbentuk pada unit penangkapan yaitu jenis ikan dari famili Carangidae (selar, kuweh), peperek (Leiognathus spp), layur, (Lepturacanthus savala), alualu (Sphyraena jello), dan talang-talang (Scomberoides commersonnianus) memangsa 50\%-90\% krustase, moluska dan nekton yang berukuran kecil. Beberapa jenis ikan lainnya seperti ikan kembung laki-laki (Rastrelliger kanagurta), tembang (Sardinella gibbosa), lemuru (Sardinella lemuru), kerong-kerong (Leptojulis cyanopleura), dan cumi-cumi (Loligo sp) memangsa beberapa fitoplankton, zooplankton, juvenil ikan dan juvenil krustase. Jenis ikan teri (Stolephorus sp) memakan $100 \%$ zooplankton. Udang putih (Penaeus indicus) memakan $77 \%$ zooplankton dan lebihnya adalah fitoplankton. Menurut Bubun et al. (2015) bahwa tropik level yang terbentuk pada perikanan light fishing yaitu TL 3,2-4,2 up. Tropik level yang terbentuk pada unit penangkapan pukat cincin, dapat dijelaskan bahwa jenis ikan lemadang (Coryphaena hippurus), madidihang (Lutjanus Sp), tongkol komo (Euthynnus affinis) dan cakalang (Epinephelus Sp) adalah memangsa 95\% $100 \%$ nekton, dan hanya $0,4 \%$ memakan zooplankton dan moluska. Jenis ikan kembung laki-laki (Rastrelliger kanagurta) memangsa dari golongan zooplankton sebanyak 55\%, selebihnya adalah nekton, fitoplankton, detritus dan juvenil krustase. Jenis ikan selar bentong (Selar crumenophthalmus) memakan hampir semua biota berukuran kecil yang terdapat di daerah penangkapan ikan. Cumicumi memangsa jenis ikan kecil seperti teri dan beberapa udang. Simbolon dan Alimina (2008) menjelaskan bahwa penangkapan Lutjanus $\mathrm{Sp}$ dengan pancing tonda dapat menggunakan umpan yang terdiri dari jenis ikan selar (Selaroides $s p$ ), layang (Decapterus $s p$ ), tongkol (Euthynnus sp), ikan terbang (Cypsilurus sp) dan cumi-cumi (Loligo $s p$ ). Syahdan et al. (2007) menyebutkan bahwa penangkapan Epinephelus Sp menggunakan umpan ikan tembang (Sardinella $s p$ ), Ikan teri (Stolephorus sp), dan ikan layang (Decapterus $s p)$.

Berdasarkan hasil tersebut dapat dijelaskan bahwa jenis ikan selar, layang, tongkol, dan cumi-cumi yang terdapat di daerah penangkapan ikan merupakan mangsa dari jenis Epinephelus Sp dan Lutjanus Sp. Proses pemangsaan ini dapat terjadi antara satu spesies dengan spesies lainnya dan dapat pula terjadi dalam satu spesies yang dikenal dengan istilah predator. Umumnya ukuran ikan yang lebih kecil menjadi mangsa bagi ikan-ikan yang berukuran lebih besar. Dalam struktur pemangsaan tropik level tersebut berada pada posisi jenis hewan karnivora dan predator. Jenis biota yang termakan umumnya dari golongan biota yang berukuran kecil seperti juvenil ikan, juvenil krustasea, ikan teri (nekton), moluska (cumi) dan beberapa plankton.

\section{Daerah Penangkapan Ikan Mengguna- kan Light Fishing}

Pada spesies ikan yang fototaksis positif terhadap cahaya umumnya adalah jenis ikan pelagis seperti Decapterus sp, Rastrelliger sp, Sardinella sp, Selaroides sp, Coryphaenidae $\mathrm{sp}$, Euthynnus affinis, Lutjanus $\mathrm{Sp}$, dan Epinephelus Sp. Interaksi fisik antara spesies dengan cahaya (light fishing) dapat menarik beberapa spesies yang berasal dari dasar perairan datang mendekati cahaya tersebut. Interaksi fisik antara spesies dengan cahaya lampu pada unit penangkapan (light fishing) memberikan pengaruh secara tidak langsung terhadap interaksi biologi antara spesies dengan spesies lainnya (Simbolon et al. 2010). Keanekaragaman spesies di daerah penangkapan ikan ditentukan oleh tingkah laku ikan di perairan terhadap kondisi lingkungannya. Tingkat konsentrasi klorofil-a di perairan dapat dijadikan indikator kesuburan perairan yang mempengaruhi keanekaragaman kompo- 
sisi hasil tangkapan ikan. Fitoplankton sebagai sumber klorofil-a menjadi rantai pertama dalam rantai makanan pada ekosisitem laut. Semakin tinggi konsentrasi klorofil-a di perairan maka komposisi hasil tangkapan ikan semakin banyak (Simbolon et al. 2009). Besarnya biomassa fitoplankton di perairan menghasilkan sumber makan utama bagi zooplankton dan juvenil di perairan. Kondisi ini menjadi daya tarik bagi spesies pemakan plankton untuk berada di sekitar daerah penangkapan ikan.

Hasil kajian sampel air (Bubun et al, 2015) menunjukkan bahwa di daerah penangkapan ikan dengan bantuan banyak terdapat plankton yang menjadi sumber makanan bagi ikan. Kondisi ini menjadi salah satu faktor yang menarik perhatian ikan untuk berkumpul di sekitar cahaya tersebut karena banyak terdapat mangsa untuk dimakan. Interaksi fisik antara spesies dengan cahaya lampu pada unit penangkapan ikan (light fishing) memberikan pengaruh secara tidak langsung terhadap interaksi biologi antara spesies dengan spesies lainnya dalam proses pemangsaan. Beberapa penelitian mengenai tingkah laku ikan terhadap cahaya menyebutkan bahwa jenis ikan pelagis, krustasea dan moluska sebagian besar memiliki sifat fototaksis posistif yang kuat terhadap cahaya dengan iluminasi tinggi (Rosyidah et al. 2011, Fauziyah et al. 2012, Yuda et al. 2012, Sudirman et al. 2003). Hasil pengamatan di lapangan menunjukkan spesies ikan mulai berada di daerah peangkapan ikan pada pukul 00.00 WITA menjelang matahari terbit dan waktu matahari terbit pada pukul 04.00 WITA sudah tidak terlihat di sekitar daerah penangkapan ikan. Intensitas cahaya lampu pada saat menjelang matahari terbit menjadi lebih rendah akibat munculnya cahaya matahari. Berdasarkan hal tersebut dapat dikatakan bahwa spesies ikan termasuk dalam golongan spesies yang menyukai cahaya lampu dengan iluminasi rendah.

Terbentuknya daerah penangkapan ikan pada perikanantangkap dengan bantuan cahaya (light fishing) disebabkan adanya interaksi fisik antara spesies dengan cahaya yang bersumber dari lampu merkuri pada unit penangkapan light fishing. Tingkah laku ikan terhadap cahaya lampu di daerah penangkapan ikan yaitu bergerak mengelilingi cahaya dan cenderung membentuk lingkaran. Sulaiman $e t$ al. (2006) menjelaskan bahwa kelompok ikan ada yang langsung menuju cahaya dan ada yang tidak, kelompok ikan datang dari berbagai kedalaman sesuai kedalaman renang masing-masing spesies. Baskoro dan Effendi (2005) menjelaskan bahwa kelompok ikan yang langsung mendekati cahaya umumnya spesies ikan yang berfototaksis positif terhadap cahaya dan yang tidak langsung mendekati cahaya umumnya spesies yang mencari makan disekitar cahaya. Simbolon et al. (2009) menjelaskan bahwa tingkat gerombolan ikan dan ketertarikan ikan pada sumber cahaya bervariasi antarjenis ikan. Perbedaan secara umum disebabkan faktor phylogenetic, ekologi dan karasteristik fisik sumber cahaya. Panjang gelombang cahaya yang dapat diterima oleh indera penglihatan pada ikan dari 400 sampai 700 nanometer. Untuk tujuan menarik ikan dalam luasan yang seluas-luasnya maka dapat menggunakan cahaya berwarna biru, sebab cahaya tersebut mempunyai panjang gelombang yang pendek dari 450 sampai 500 nanometer namun frekunsi paling jauh, sehingga dapat menarik perhatian ikan secara vertikal dan horisontal secara luas. Setelah ikan terkumpul di daerah jangkauan alat tangkap (cathchability area), cahaya merah dapat digunakan untuk menarik ikan lebih mendekati sumber cahaya, sebab panjang gelombangnya lebih panjang dari cahaya lainnya yaitu 650 sampai 700 nanometer namun frekuensinya pendek sehingga ikan lebih terpusat pada cahaya warna merah dan ruang gerak ikan menjadi lebih sempit. Kondisi ini dapat dimafaatkan oleh nelayan untuk mulai mengoperasikan alat tangkapnya sehingga kegiatan penangkapan lebih efektif.

Spesies yang menyukai cahaya dengan iluminasi rendah dan berada di daerah penangkapan ikan karena terdapat mangsa untuk dimakan, digolongkan dalam spesies yang berinterakasi secara biologi dengan lingkungannya. Kombinasi interaksi fisik dan biologi secara umum terjadi pada semua spesies di daerah penangkapan ikan dengan bantuan cahaya (light fishing). Namun, spesies yang fototaksis positif kuat terhadap cahaya lebih dominan dalam kombinasi interaksi tersebut. Hal ini disebabkan spesies tersebut tertarik dengan iluminasi cahaya yang tinggi dan golongan spesies tersebut saling berinteraksi dalam proses pemangsaan. Spesies 
tsersebut terdiri dari ikan pelagis dan demersal. Proses terbentunya daerah penangkapan ikan dengan bantuan cahaya (light fishing) menciptakan komposisi yang beranekaragam spesies dan ukuran ikan. Brown et al. (2011) menjelaskan rantai makanan merupakan jaringan yang dari satu spesies dengan spesies lainnya dalam interaksi pemangsaan. Interaksi antara spesies dalam rantai makan menyebabkan terjadinya perpindahan energi dan hubungan ukuran metabolisme menyebab komunitas memiliki struktur tropik tertentu. Odum (1998) menjelaskan bahwa pada pemangsaan dalam ekosistem laut, semua nekton dewasa adalah karnivora yang memangsa plankton yang lebih kecil atau nekton lainnya.

Proses pemangsaan oleh nekton yang berukuran besar menjadi predator bagi nekton lainnya. Salah satu sifat yang paling konsisten dari cara makan ikan nektonik yaitu tidak selektif dalam memangsa sebab semua ukuran makanan yang tersedia di perairan menjadi makanannya. Kombinasi antara interaksi fisik spesies dengan lingkungannya dan interaksi biologi antara spesies dengan spesies lainnya telah membentuk daerah penangkapan ikan yang optimal pada malam hari.

\section{KESIMPULAN}

Dari hasil penelitian ini dapat disimpulkan bahwa:

1. Lampu LED pada kapal penangkap ikan memberikan hasil tangkapan yang lebih banyak sekitar 22,30\% dibandingkan dengan kapal penangkap ikan yang tanpa menggunakan lampu.

2. Dengan demikian kapal perikanan yang diberikan kepada nelayan sebagai kapal bantuan akan dapat dimanfaatkan secara maksimal oleh nelayan baik melakukan penangkapan pada saat siang hari atau malam hari.

3. Pada awal lampu mulai dinyalakan maka ikan datang ke sumber cahaya. Namun ikan hanya bertahan sebentar kemudian menghilang lagi. Pukul 00.00 sampai 04.00 merupakan waktu yang baik untuk dilakukan penangkapan ikan dengan menggunakan rangsangan lampu di atas air. Pergerakan ikan terjadi secara tidak beraturan pada waktu mencari makan namun pada kemunculannya, ikan tam- paknya tetap bertahan di bawah sumber cahaya.

4. Dengan pertimbangan jumlah hasil tangkapan dan aspek teknis operasional pemanfaatan lampu listrik pada kapal penangkap ikan, terutama lampu LED layak untuk dikembangkan dalam rangka pengembangan perikanan tangkap. Kekuatan cahaya dan warna lampu LED yang tepat, untuk diguanakan sebagai alat bantu penangkapan ikan masih perlu diteliti.

\section{DAFTAR PUSTAKA}

Aida Sartimbul, Erfan Rohadi, Siva N. Ikhsani, Devita Listiyaningsih. 2018. Morphometric and meristic variations among five populations of Sardinella lemuru Bleeker, 1853 from waters of Bali Strait, northern and southerneast Java and their relation to the environment. AACL Bioflux, 2018, Volume 11, Issue 3.

Allen G, Roger, Ruse, Swainston J. 2000. Marine Fishes of South-east Asia: a Field Guide for Anglers and Divers. Periplus Edition Ltd.

Baskoro M, Effendi A. 2005. Tingkah Laku Ikan Hubungannya dengan Metode Pengoperasian Alat Tangkap Ikan. Departemen Pemanfaatan Sumberdaya Perikanan. Fakultas Perikanan dan Ilmu Kelautan. Bogor (ID). Institut Pertanian Bogor.

Brown LE, Edwards FK, Milner AM. 2011. Food Web Complexity And Allometric Scaling Relationships in StreammesoCosms: Implications For Experimentation. Journal of Animal Ecology. 80:884895

Fauziyah, Saleh K, Hadi, Supriyadi F. 2012. Respon Perbedaan Cahaya Intensitas Cahaya Lampu Petromak Terhadap Hasil Tangkapan Bagan Tancap di Perairan Sungsang Sumatera Selatan. Maspari Journal. 4(2):215-224

Jacobsen IP, Bennett MB. 2013. A Comparative Analysis of Feeding And Trophic Level Ecology in Stingrays (Rajiformes; Myliobatoidei) and electric 
rays (Rajiformes; Torpedinoidei). Plos ONE. 8(8):e71348.doi:10.1371 /journal.pone.0071348.

Jibran, A. Syamsudin 2013. Potensi Perikanan Purse Seini di Wilayah Kabupaten Banggai, Sulawesi Tengah. Fakultas Perikanan dan Ilmu kelautan, Universitas Hasanuddin, Makasar.

Nontji. 2007. Laut Nusantara. Jakarta (ID). Djambatan.

Odum. 1998. Dasar-dasar Ekologi. Edisi ketiga. Gajah Mada University Press.

Pauly D, Trites AW, Capuli E, Christensen V. 1998. Diet composition and trophic levels of marine mammals. ICES Journal of Marine Science. 55:467-481.

Ridwan Sala. 2017. Relative abundance of skipjack tuna (Epinephelus Sp L.) in waters around Sorong and Fak-Fak, West Papua, Indonesia. AACL Bioflux, 2017, Volume 10, Issue 3.

Ririn Irnawati, Dini Surilayani, Adi Susanto, Aris Munandar, Ani Rahmawati. 2018. Potential yield and fishing season of anchovy (Stolephorus sp.) in Banten, Indonesia. AACL Bioflux, 2018, Volume 11 , Issue 3.

Rosyidah IN, Farid A, Nugraha WA. 2011. Efektivitas Alat Tangkap Mini Purse Seine Menggunakan Sumber Cahaya Berbeda Terhadap Hasil Tangkapan Ikan Kembung (Rastrelliger $s p$ ). Jurnal Ilmiah Perikanan dan Kelautan. 3(1):41-45.

Simbolon D, Alimina N. 2008. Analisis Perikanan Pancing Tonda Madidihang (Lutjanus Sp) di Perairan Bagian Selatan Sulawesi Tenggara. Buletin SWIMP Akademi Perikanan Sorong. Juni 2008.8:1824

Simbolon D. 2009. Analisis hasil tangkapan ikan cakalang hubungannya dengan konsentrasi klorofil-a di Perairan Binuangeun Banten. Buletin SWIMP Akademik Perikanan Sorong. Juli 2009.10:28-32

Simbolon D, Irmawati R, Sitanggang LP, Ernaningsih D, Tadjuddah M, Manoppo VEN, Kaman, Mohammad. 2009. Pem- bentukkan Daerah Penangkapan Ikan. Departemen Pemanfaatan Sumberdaya Perikanan. Fakultas Perikanan dan Ilmu Kelautan. Bogor (ID). Institut Pertanian Bogor

Simbolon D, Sondita MFA, Amiruddin. 2010. Komposisi isi saluran pencernaan ikan teri (Stolephorus spp.) di Perairan Barru, Selat Makassar. Indonesian Journal of Marine Science. 15(1):7-16.

Simbolon D. 2011. Bioekologi dan Dinamika Daerah Penangkapan Ikan. Departemen Pemanfaatan Sumberdaya Perikanan Fakultas Perikanan dan Ilmu Kelautan. Bogor (ID). Institut Pertanian Bogor.

Sudirman, Baskoro MS, Purbayanto A, Monintja DR, Jufri M, Arimoto T. 2003. Adaptasi Retina Mata Ikan Layang (Decapterus Ruselli) Terhadap Cahaya Dalam Proses Penangkapan Pada Bagan Rambo di Selat Makassar. Jurnal Ilmuilmu Perairan dan Perikanan. Desember 2003. 10(2):85-92

Sudirman, Baskoro MS, Purbayanto A, Monintja DR, Rismawan W, Arimoto T. 2004. Respon Mata Ikan Teri (Stolephorus Insularis) Terhadap Cahaya Dalam Proses Penangkapan Pada Bagan Rambo. Jurnal Torani. 4(3):1-14

Sudirman, Nessa MN. 2011. Perikanan Bagan dan Aspek Pengelolannya. Malang (ID). Universitas Muhammadiyah Malang (UMM) Press.

Sugiyono. 2013. Metode Penelitian Kombinasi (Mixed Methods). Bandung (ID). Alfabeta Bandung.

Sulaiman M, Jaya I, Baskoro MS. 2006. Studi Tingkah Laku Ikan Pada Proses Penangkapan Dengan Alat Bantu Cahaya: Suatu Pendekatan Akustik. Indonesian Journal of Marine Fisheries. 11(1):31-36

Syahdan M, Sondita MFA, Atmadipoera A, Simbolon D. 2007. Hubungan Suhu Permukaan Laut dan Klorofil-A Terhadap Hasil Tangkapan Cakalang (Epinephelus Sp) Di Perairan Bagian Timur Sulawesi Tenggara. Buletin PSP. XVI (2):246-260 
Tupamahu, A. 2003. Studi Tentang Tingkah Laku Ikan Tembang (Sardinella Fimbriata) dan Selar (Selar Crumnepthalmus) Di Bawah Cahaya Lampu. Disertasi. Program Pascasarjana IPB, Bogor.
Yuda LK, Iriana D, Khan AMA. 2012. Tingkat Keramahan Lingkungan Alat Tangkap Bagan di Perairan Palabuhanratu Kabupaten Sukabumi. Jurnal Perikanan dan Kelautan. 3(3):7-13. 